\title{
Quotas for Men: Reframing Gender Quotas as a Means of Improving Representation for All RAINBOW MURRAY Queen Mary University of London
}

\begin{abstract}
$G$ ender quotas traditionally focus on the underrepresentation of women. Conceiving of quotas in this way perpetuates the status of men as the norm and women as the "other." Women are subject to heavy scrutiny of their qualifications and competence, whereas men's credentials go unchallenged. This article calls for a normative shift in the problem of overrepresentation, arguing that the quality of representation is negatively affected by having too large a group drawn from too narrow a talent pool. Curbing overrepresentation through ceiling quotas for men offers three core benefits. First, it promotes meritocracy by ensuring the proper scrutiny of politicians of both sexes. Second, it provides an impetus for improving the criteria used to select and evaluate politicians. Third, neutralizing the overly masculinized environment within parliaments might facilitate better substantive and symbolic representation of both men and women. All citizens would benefit from these measures to increase the quality of representation.
\end{abstract}

A $t$ the core of democracy is the representation of society by an elected group of politicians. To ensure that democracy functions optimally, representation should be of the highest possible quality. This entails selecting the best politicians through meritocratic recruitment processes. Although this ideal attracts consensus, its details-such as how to define quality, and whether representation should be evaluated at the individual, group, or institutional level-are controversial. Currently, the composition of most legislatures is dominated by wealthy, ethnic-majority men. The ability of such legislatures to represent society in all its diversity is contested. Further, the narrow social composition of legislatures suggests either that certain groups within society are less capable of representing others or that something has gone awry in the recruitment process.

Favoring the latter hypothesis, gender quotas have been introduced widely as one means of correcting imbalances in representation. The emphasis within gender quotas typically lies with addressing women's underrepresentation. Gender quotas raise serious questions about the quality of representation; advo-

Rainbow Murray, Queen Mary University of London (rainbowmurray@gmail.com)

Earlier drafts of this article were presented at the Political Studies Association (PSA) annual conference, Belfast, April 2012; at the PSA Women and Politics specialist group conference, Bristol, February 2012; (virtually) at the American Political Science Association annual meeting, New Orleans, August 2012; and at the University of Bournemouth, February 2013. I am thankful to all the participants for their valuable feedback, and especially to Alistair Clark and Melanie Hughes for their detailed comments. The paper on which this article is based received the APSA Women and Politics Research Best Paper Award 2013 (Honorable Mention), and I thank Miki Caul Kittilson (chair) and the members of the award committee for their consideration of my paper. Peter Allen, Tim Bale, Sarah Childs, Michael Kenny, Robin Pettitt, and Heather Savigny all gave generous support, and I thank them all for their close reading of the draft manuscript and their helpful insights. I am grateful to the editors of the American Political Science Review and to each of the five anonymous reviewers for their extremely helpful and insightful comments. This article benefited immeasurably from this feedback. Last but not least, my thanks go to Alicia Murray-Pettitt, to whom this article is dedicated. cates argue that they enhance the substantive and symbolic representation of women, whereas detractors claim that they prioritize group representation at the expense of meritocracy. However, insufficient consideration is given to the limitations of the maledominated status quo for providing high-quality representation for both sexes. Male overrepresentation itself compromises meritocracy and constrains the substantive representation of men as well as women. Debates on quotas therefore need to pay more attention to dominant groups.

Many gender quotas are framed explicitly as quotas for women. Even when quotas are framed in gender-neutral language (for example, demanding that a party list contain no fewer than $40 \%$ candidates of either sex), rather than targeting women explicitly, the discourse surrounding gender quotas has focused on the underrepresentation of women (Dahlerup 2006; Dahlerup and Friedenvall 2005). ${ }^{1}$ Because underrepresentation is a problem that affects only women and not men due to long-standing gender inequalities, the use of gender-neutral language does not conceal the fact that quotas focusing on underrepresentation are effectively quotas for women (cf. Zimmer 1988). Even if reducing the overrepresentation of men is a necessary corollary of increasing women's presence, it is never presented as the primary goal with its own intrinsic benefits. Rather, the justification for gender quotas focuses on the need to increase women's presence.

The thesis presented here is that this is a problematic approach to gender quotas. The focus on women's underrepresentation has the unintended consequence of framing men as the norm and women as the "other." With men's presence already accepted as the status quo, the burden of proof for justifying presence lies with the outsiders wishing to enter politics (women), rather than with those already present in excessive numbers (men). Men are required neither to prove their competence nor to justify their inclusion. This

\footnotetext{
${ }^{1}$ Bjarnegård (2013) does focus on male overrepresentation, but not within the context of gender quotas.
} 
is not to say that individual men are immune to all scrutiny, but rather that the competence of men as a category is not questioned. Women, in contrast, are placed under close scrutiny to ascertain whether they "deserve" a greater presence in politics. This prompts critics of quotas to fear that "quota women" may be inferior because of perceptions that they are less well qualified for office, have not had to battle as hard to enter, and/or have been selected for office only on the basis of their sex rather than their more tangible qualities (Bacchi 2006; Karam 1999; Zetterberg 2008). Men have escaped the same criticisms, even though they have long been the beneficiaries of preferential selection based on sex.

To resolve this dilemma, I propose that we reframe gender quotas, moving from implicit quotas for women to explicit quotas for men. This entails a shift in emphasis from the problem of underrepresentation to the problem of overrepresentation. Overrepresentation of a particular group can have a deleterious effect on the quality of representation because of its restriction of the talent pool to a narrow subsection of society. Expanding the talent pool to all sectors of society would enhance representation for everyone by achieving a genuine (rather than spurious) meritocracy in which only the very best will succeed.

An inevitable consequence of approaching quotas in this way is that the number of men would need to be reduced to their appropriate share of representation $(50 \%)$. This would, of course, also be the case for a gender quota where the emphasis was on raising women's presence to $50 \%$. However, the distinctive feature of a focus on overrepresentation is that it shifts onto men the onus to prove their worth and justify their coveted place within politics. To fulfill the normative goal of the quota (enhancing the quality of representation), the reduction of men's presence needs to be made on the basis of transparent, objective criteria concerning what constitutes a good representative. At present, selection criteria are seldom codified and are often based on outdated notions of the skills and qualifications required to represent others. Thus, an essential first step is to reappraise the qualities required of a representative. This, in itself, could potentially transform the way that we conceptualize representative democracy.

This article combines normative political theory with an analysis of practical repercussions to demonstrate the limitations of the current focus on quotas for women. Reframing the debate is desirable both normatively-highlighting and addressing weaknesses in current approaches-and politically, by offering a new way to challenge the damaging effects of overrepresentation. A closer examination of meritocracy further exposes flaws in the status quo. Not only are current notions of merit discriminatory, because they are applied unevenly to men and women and are based on elite male norms, but they also overlook certain qualities that are important for substantive and symbolic representation. Although few would deny the benefit of selecting the most meritorious candidates, ${ }^{2}$ there is

\footnotetext{
$\overline{2}$ An exception might be advocates of random selection and sortition.
}

little consensus on the criteria necessary to achieve an optimal set of representatives. Meanwhile, research on gender quotas and representation tends to focus on women at the expense of men and does not sufficiently challenge existing notions of merit. Bringing together these complementary perspectives permits a different way of thinking about gender quotas that addresses some of the conceptual and pragmatic difficulties presented by existing approaches.

In the next section, I offer a more in-depth discussion of the disadvantages of current ways of conceiving of gender quotas, explaining why they are problematic for women, do not apply sufficient scrutiny to men, and operate on a flawed (and often untested) assumption of meritocracy. I then present the thesis of quotas for men in more detail, outlining the three core benefits of such an approach. First, reframing gender quotas in this way necessitates the proper scrutiny of male as well as female politicians. Second, it opens a debate on the true qualities required to be effective representatives. I offer a first step toward reimagining the criteria for what makes a "good" representative in order to provide a more contemporary and objective definition of meritocracy. Third, this new approach promotes better representation of the substantive interests of both women and men. By enhancing rather than undermining meritocracy, quotas for men serve to raise the quality of representation for everyone.

\section{WHY "QUOTAS FOR WOMEN" ARE PROBLEMATIC}

Carver (1996) reminds us that "gender is not a synonym for women." Yet, when we think of gender quotas, there is an ingrained association with quotas for women. Because men are not underrepresented, they are not perceived to require a quota mechanism. Quotas are usually viewed as a means of ensuring a minimum presence of the target group (in this case, women), rather than a means of controlling the number of members of overrepresented groups (Dahlerup 2006; Jones 1998; Lovenduski 2005). Discourse surrounding quotas tends to problematize the shortage of women in politics and to present quotas as a solution, leading to an indelible association of gender quotas with women (Tinker 2004; Tripp and Kang 2008).

Although quotas for women are often seen as a practical solution to women's underrepresentation, the causes of political gender imbalance are multiple and complex. Much scholarship has been devoted to the structural and systematic variables restricting women's access to politics. For example, Norris and Lovenduski (1995) explore how women's underrepresentation is a problem both of lack of supply (qualified women do not come forward) and lack of demand (when women do come forward, political gatekeepers overlook them in favor of men). Differential access to resources, including money, education, free time, and encouragement from others, reduces the supply of women candidates. ${ }^{3}$

\footnotetext{
${ }^{3}$ Education is seldom a problem for women in contemporary Western democracies, with women succeeding in education in levels that
} 
Lawless and Fox (2010) highlight how women are socialized into having lower levels of political ambition, whereas men benefit from greater confidence and aspiration. Demand-side factors may also present themselves in the form of direct and/or imputed discrimination (Norris and Lovenduski 1995). Not only will such behavior have a direct effect on women's presence in politics but it may also discourage future women from emerging as candidates. So, too, may the lack of role models for raising young women's aspirations. Instead, potential female candidates are likely to be deterred by instances of public humiliation of women politicians in legislatures and the media (Denis 2012; Elliott 2011; Falk 2008; Lawrence and Rose 2010; Murray 2010a).

For a wide variety of well-established reasons, therefore, the path into office is more challenging for women than men. The many obstacles preventing women's full political inclusion offer ample evidence that the current system is not a meritocracy. Acknowledging that women compete on an unequal playing field, the purpose of gender quotas has been to overcome these hurdles for women. Quotas have the potential to suppress demand-side resistance to women candidates and to boost supply by fostering a more welcoming, inclusive environment.

Achieving a rapid increase in the number of women politicians might necessitate widening the search beyond traditional political pipelines. Although I argue later that this widening is to be welcomed, it also gives rise to one of the most common popular critiques of gender quotas, namely that they favor the promotion of inferior women candidates at the expense of more qualified men (Celis, Krook, and Meier 2011; Dahlerup and Freidenvall 2010; Franceschet, Krook, and Piscopo 2012). This fear arises from a belief, despite evidence to the contrary (Baltrunaite et al. 2012; O'Brien 2012), that the current system is meritocratic and that those who make it into politics must, as evidenced by their success, be the most worthy. Many of those already present in politics, including some women, justify their presence on these grounds. Indeed, the success of some women in politics is construed as evidence that the system is fair: If these women can penetrate the world of politics, this proves that talent is rewarded, and if other women were likewise meritorious, they too would surely succeed. Examples of successful women politicians, such as Margaret Thatcher (British prime minister from 1979-90), are often offered as proof that women can make it to the top as long as they are good enough. The paucity of women in politics, on this view, must be due to a lack of merit, and forcing underqualified women into politics to satisfy a quota would be detrimental to the quality of political institutions and a threat to democracy. A woman elected via a quota

often exceed men (UNESCO 2010). There is some gender segregation regarding topics studied, with men predominant in math and science, whereas most women favor arts and humanities subjects. In developing regions (notably South and West Asia and sub-Saharan Africa), women may still not enjoy equal educational opportunities to men, and historical differential access to education in Western societies may have a lingering effect in older generations. might not be the "best man for the job" but merely the best woman and therefore might lack the experience, appropriate background, and ability to fight for political gains. Even if women did possess these qualities, the association with gender quotas might undermine their talents, leading to the suspicion that they had not made it purely on their own merit (Krook 2006; O'Brien 2012).

The arguments against quotas, based on meritocracy, assume (albeit sometimes implicitly) that the significant overrepresentation of men, over time and space, is the correct and fair outcome. This assertion is frequently contested by quota advocates, who sometimes even argue that women have to be significantly more deserving than men to overcome the many barriers to their presence (Dahlerup 2007; Escobar-Lemmon and Taylor-Robinson 2009; Franceschet and Piscopo 2014). A much less commonly aired argument is that men receive an unfair advantage in accessing political power. If the playing field is not, in fact, level, then men may themselves be accessing politics on the basis of their sex rather than their more tangible qualities. As such, they may not be the best person for the job, but merely the best man. Hence, the threat to the quality of representation comes not from redressing the imbalance of the sexes, but from allowing it to persist unchecked.

One reason why the belief in an existing meritocracy persists is because exposing its fallacy is surprisingly complex. A pressing concern for women seeking to establish their credentials is how to prove the existence of merit. Men are less frequently challenged by this dilemma: As the traditional status quo, they benefit both from the presumption of competence and from greater opportunity to demonstrate their worth. The most convincing way of demonstrating competence is by performing the required task. Because men are already in a position to perform the task of representation and because the criteria for success are based on previous (male) examples, men have an inherent advantage in showcasing their talent. Indeed, their existing presence in politics is taken as sufficient evidence of their ability to serve as representatives. Thus, men's competence is rarely called into question, and their traits and qualifications are seldom subjected to close scrutiny qua men. Conversely, women frequently find themselves needing to prove their worth qua women; they do not benefit from the same presumption of competence and indeed may find themselves having to disprove gendered preconceptions of inadequacy (Dahlerup 2007; Kanter 1977; Stevens 2012).

Placing the burden of proof on women is a double disadvantage. Not only are they less likely to have their competence taken as a given and more likely to be expected to justify their presence but they are also less well placed to do so. The difficulty for "outsiders" in demonstrating their capacity to be effective representatives is exacerbated if the criteria for proving merit are derived from the dominant, "insider" group (Bacchi 1996). Getting more women into political office via a gender quota has the benefit of giving women an opportunity to demonstrate their competence by performing the role (Bhavnani 2009). 
However, the problem remains that women's value may be undermined by the suspicion that they owe their presence solely to a quota rather than talent. This enduring belief, despite research showing the contrary (Besley et al. 2012; Murray 2010b), indicates that evidence is necessary but not sufficient; the public debate must be reframed.

Women may find themselves faced with a further burden. Even if women are considered to be equally qualified for political office, they may still face additional expectations in order to justify expelling existing officeholders (who may also be deemed worthy) to make way for new entrants. Phillips (1995) argues that the question of justice is sufficient to justify women's inclusion in politics, without need for further arguments. However, for those who consider it an injustice to remove incumbents from office through no wrongdoing of their own, the argument for including more women on the grounds of justice alone may not be sufficiently persuasive, even if it cannot be refuted outright. Instead, women may find themselves needing to demonstrate that they are not directly equivalent to men. Equality arguments based on women's equal merit, underpinned by claims for justice, have often become subjugated in public quota debates to arguments focusing on difference; for example, Teigen recommends "stressing ... the special contribution of women" $(2000,63)$. It is not sufficient for women to be interchangeable with men; they are expected to offer something distinctive, without which the democratic process is incomplete, thus necessitating their presence. Sénac-Slawinski (2010) refers to this as "added value," with women needing to demonstrate that they meet all the same criteria as men, while also providing additional roles as substantive and symbolic representatives of women. Such a strategy is essentializing and can be problematic for female legislators, who may feel compelled to conform to institutional norms and avoid being associated with the narrow representation of sectoral interests (Childs 2004; Larson 2012; Lovenduski 2005; Walsh 2012). There is no equivalent expectation of male legislators, because the substantive and symbolic representation of men are normally taken for granted within male-dominated legislatures.

Scholars of gender and politics may inadvertently contribute to these additional expectations of women, with much work measuring possible relationships between the descriptive and substantive representation of women (Celis 2006; Reingold 2006; Swers 2005). Although recent scholarship has sought to disassociate descriptive and substantive representation, arguing that women's bodies are neither a guaranteed nor an exclusive conduit for feminist minds (Celis et al. 2008; Childs 2006; Childs and Webb 2012), there is still solid evidence that women do need women representatives (Campbell, Childs, and Lovenduski 2010). Consequently, women representatives find themselves faced with a triple whammy: They are expected to be as good as men on traditional male-oriented criteria, while also providing added value, yet may still be perceived as inferior to their male colleagues and have their competence constantly questioned.
In contrast, men benefit from their position as the dominant group by being able to set the rules of the game, with themselves as the established players. Scrutiny of political credentials tends to focus on the challengers to the status quo (women), rather than on its upholders (men). Phillips challenges the presumption that men automatically belong in office, arguing instead that we should

turn the argument around, and ask by what "natural" superiority of talent or experience men could claim a right to dominate assemblies? The burden of proof then shifts to the men, who would have to establish either some genetic distinction which makes them better at understanding problems and taking decisions, or some more socially derived advantage which enhances their political skills. Neither of these looks particularly persuasive; the first has never been successfully established, and the second is no justification if it depends on structures of discrimination. (Phillips 1995, 65)

If men do not enjoy a "natural superiority of talent," it is unsafe to assume that a legislature comprised disproportionately of men provides the ideal balance for good representation. We cannot automatically infer that men are present in these proportions because they were the best representatives available. Baltrunaite et al. (2012) find that feminizing legislatures through quotas leads to an increase in the quality of both male and female politicians, a finding supported by Besley et al. (2012) and Júlio and Tavares (2010), suggesting that the composition of legislatures pre-quotas was suboptimal.

Problems in male-dominated legislatures include corruption, with politicians in various countries accused of bribery, clientelism, fiddling expenses, and abusing power (Bale and Caramani 2010; Bjarnegård 2013; Caramani, Deegan-Krause, and Murray 2011). These scandals parallel similar problems in other sectors such as banking and finance, where the maledominated culture and exclusion of female talent contributed to the recent economic crisis (Prügl 2012) and board homogeneity is associated with lower value for corporate firms (Carter, Simkins, and Simpson 2003). My argument is not that it is a gender imbalance per se that might create problems, ${ }^{4}$ but rather that male-dominated legislatures comprise a skewed sample drawn from a subsection of the population, resulting in an increased risk of selecting inferior politicians. The exclusion of alternative perspectives and cultures may also permit bad practices to persist unchecked.

Furthermore, the inadequacies of male-dominated legislatures for addressing the substantive interests of women are well documented (Childs and Withey 2006; Lovenduski 2005; Swers 1998). Although women do not monopolize the capacity to act as substantive representatives for women, they mobilize more frequently than men on issues of importance to women, and they bring perspectives to policy debates that are otherwise

\footnotetext{
${ }^{4}$ Swamy et al. (2001) and Dollar, Fisman, and Gatti (2001) did find some evidence that women are less involved in corrupt practices than men, although these findings have been contested (Bjarnegård 2013; Sung 2003)
} 
lacking (Franceschet and Piscopo 2008; Mansbridge 1999; Sapiro 1981; Schwindt-Bayer 2010). Legislatures dominated by male elites also pose problems for symbolic representation, because they may lead to a sense of political alienation among members of excluded groups (Franceschet, Krook, and Piscopo 2012).

The narrowness of politicians' backgrounds may further undermine the legitimacy of political institutions (Dovi 2007). Studies indicate a loss of citizen engagement with institutions perceived as too remote from their daily lives (Karp and Banducci 2008). Verba, Burns, and Schlozman (1997) found that greater gender balance in politics was mirrored in more genderbalanced levels of political knowledge within the general population; similarly, a better gender balance of political candidates increases women's political engagement and participation (Atkeson 2003; Norris, Lovenduski, and Campbell 2004). However, if people do not recognize themselves within the institutions purporting to represent them, they may disengage altogether from the political process (Henn, Weinstein, and Hodgkinson 2007; O’Toole, Marsh, and Jones 2003). Legislatures that are unrepresentative in areas such as gender, race, and class have contributed to democratic malaise, evidenced by declining levels of voter turnout, public disenchantment with politics, and a desire for change and political renewal (Baldez 2004, 2006; Saward 2010).

Yet, public disillusionment with politics tends to be linked to gender only through the substantive and symbolic representation of women, whereby legislatures are criticized for neglecting women's interests and perspectives and for not providing a mirror of society. There is far less debate about whether imbalanced legislatures are failing everyone, across the full range of policy areas and representative acts, as a result of limiting political recruitment to a subsection of society. In other words, the competence of male legislators is seldom questioned even when the effectiveness of male-dominated legislatures as a whole is seen to be undermined.

\section{QUOTAS FOR MEN}

A central tenet of this article is that the overrepresentation of any group is unfortunate, not only because of the corresponding deficit of another group but also in and of itself. Selecting too many people from a restricted talent pool is intrinsically problematic because it compromises the quality of representation for everybody. Solving this problem requires a solution that focuses on restricting overrepresentation, rather than redressing underrepresentation. It necessitates a reconceptualization of quotas, whereby instead of serving as a target for an underrepresented group, they operate as a ceiling for an overrepresented group. A quota for men would indicate the maximum percentage of men who could be present in a legislature; for example, $60 \%$ or even $50 \%$. Although many existing gender quotas are framed in gender-neutral language that includes ceilings as well as floors (for example Spain, whose "parity" quota stipulates a minimum of $40 \%$ and maximum of $60 \%$ of either sex), a quota for men is distinct from a gender quota, because it emphasizes the problem of overrepresentation. Indeed, although the focus here is on quotas for men in order to highlight the normative shift away from quotas for women, a similar quota could be applied to any overrepresented group. The key distinctive feature is the normative reasoning underpinning the quota. The central concern lies not with gender equality, nor fairness, valid and important though these undoubtedly are. Instead, the emphasis is on enhancing the quality of representation for all.

If we accept Phillips' claim that men do not enjoy a "natural superiority of talent" and assume instead that most attributes are distributed fairly randomly across the population, it follows that approximately half of the best possible legislators will be men and approximately half will be women. If we restrict the talent pool of legislators only to men, we lose half of the best people for the job. If we restrict the pool further, focusing on men from elite, privileged, ethnic-majority backgrounds (as is the case in most polities), we remove from contention the majority of the top candidates. Instead of selecting the best candidates for the job, we can select only the best candidates from within the restricted talent pool. Inevitably, this results in a less competitive process, with a larger sample being drawn from a narrow subset of the population. This sample may still include the best candidates from within the subset, but it will also include candidates who would not be selected if faced with full and fair competition from the wider population. Thus, if competition is restricted to members of a narrow group, the outcome will be the selection of suboptimal candidates who would not have been competitive if operating within a genuine meritocracy. By having too many candidates from one restricted group and too few from other groups, there is an inefficient use of the overall available talent of the population. The consequence is an inferior quality of representation, which is undesirable for all citizens, both male and female.

It could be argued that the effects on quality of restricting the talent pool are marginal when the number of elected politicians is considered within the context of the overall population size. Even if the candidates selected are suboptimal, it might still be possible to find a sufficient number of strong candidates from within the restricted talent pool of men. However, this claim is not persuasive, because it is not the case that all members of the population are viable contenders for elected office. The "ladder of recruitment," introduced by Norris and Lovenduski $(1995,16)$, illustrates the filtering process present in most democracies by which the total pool of eligible citizens is reduced to a much smaller pool of potential candidates. This process is mediated by political parties, which play a key role in political recruitment and candidate selection, but the filtering principle also holds when the role of parties is less dominant. Even if aspirant candidates emerged in an equal distribution from all sectors of society, the total number of individuals possessing the qualities and motivation to succeed in electoral politics would 
be relatively low. Although the "natural superiority of talent" is not restricted to a particular social category such as men, all citizens do not possess in equal measure an aptitude for politics, any more than artistic or athletic talent is universal. If only a limited number of individuals possess political talents, it is important to include as many of those individuals as possible in the recruitment process to ensure that political institutions receive the best talent available. Within an already restricted pool of those possessing a flair for politics, the difference in quality created by excluding at least half of potential candidates is likely to be significant.

The application of a "ceiling" quota would help address this problem by restricting the number of candidates selected from one subsection of the talent pool, thus opening up the selection process to rival groups and making selection more genuinely competitive and meritocratic. Hence, a quota for men would restrict the numbers of men to help ensure that only the best candidates survive the selection process. Although the focus here is on men, the theory has potential application for the overrepresentation of other categories, such as ethnicity and class. The present problem of male overrepresentation is exacerbated by the fact that these men tend disproportionately to be from ethnicmajority and privileged economic backgrounds.

A quota is not sufficient, in itself, to guarantee a genuine meritocracy; weaker men might still triumph over more talented male rivals due to other anticompetitive aspects of the selection process such as patronage. There is also a risk that minority men might be forced out of politics to preserve places for majority men; such a move would run counter to the goals of the quota. Hence, an emphasis on merit is essential to avoid the replacement of one form of elite with another.

Meritocracy can be advanced through challenging the status quo, opening a debate about quality, and making better use of available resources of talent. For the problem of (un)fair competition to be resolved, it first must be recognized. The political priority accorded to quotas for women has masked the many problems caused by overrepresentation; however, the absence of public debate on overrepresentation does not mean that no such debate is necessary. The parallel issue of underrepresentation was also long absent from public discourse until campaigns for quotas for women highlighted the democratic deficits caused by excluding certain groups from power. A focus on overrepresentation is now needed to highlight the lack of meritocracy underpinning current imbalances and to initiate a debate on how to improve the quality of representation. Quotas for men would raise public awareness of a problem that is too frequently ignored or denied, often by those with vested interests in maintaining the status quo. Publicly highlighting the detrimental consequences of unfair competition would also help open up alternative talent pools, thus increasing the chances of selecting the best candidates for the job.

It is important to note that the argument in favor of quotas for men is not an attack on male representatives. For democracy to thrive, the presence of men is essential. Rather, the emphasis lies with achieving a more fully competitive process and enhancing the quality of representation for all. Nonetheless, these goals do necessitate a significant reduction in the number of male politicians. (The extent of the reduction required varies both in terms of the degree of overrepresentation and the level at which the ceiling is set.) Although, from a normative perspective, a $50 \%$ quota for men would be ideal (thus ensuring that the number of men elected is proportionate to the wider population), a case could be made for a little flexibility to account for natural fluctuations of talent within the population. (An overly generous ceiling, however, might present the same problems as a quota for women that is set too low, by providing a margin within which reform can be resisted.)

Determining which men to remove from office introduces both normative and practical dilemmas. Ideally, such decisions should lie with voters. In practice, candidate (re)selection decisions frequently lie with political parties. Forcing parties to deselect incumbents is arguably a restriction of the freedom both of parties to select their preferred candidate and of voters to elect their candidate of choice (Rehfeld 2010). However, these dilemmas are equally raised when seeking to implement quotas for women (Hazan and Rahat 2010; Murray 2010c). Parties implementing quotas have been obliged to modify their recruitment practices and free up seats for women candidates (Krook 2009). The difference here is that parties would have an explicit mandate to focus on quality when evaluating male candidates, rather than targeting men who were out of favor with the party for other reasons. Meanwhile, voter choice has always been restricted to the candidates preselected by political parties; voters who wished to vote for a more diverse range of candidates have been unable to do so. Although quotas for men would not automatically increase voter choice, they would encourage parties to use more meritocratic selection procedures and hence to put forward the highest caliber candidates on their tickets, thus having a fairly neutral effect on voter freedom and a positive effect on the quality of representation. A focus on meritocracy in selection procedures would still operate alongside other imperatives for parties when selecting candidates, such as the need to balance internal factions, but should complement rather than contradict these other priorities.

Given the practical difficulties for parties of forcing incumbents out of office, pragmatists might argue for reducing the number of male politicians in stages rather than enforcing an immediate cull. This approach might be defended on the grounds of fairness to existing male legislators, continuity, and conserving experience. However, Mexico does not permit legislators to serve two consecutive terms, indicating the potential for complete political renewal within a single election. Because slow implementation of a quota for men would result in an ongoing suboptimal set of legislators, it is difficult to defend on any grounds other than facilitating implementation.

For the central goal of enhancing quality to be fulfilled, it is not sufficient for the quota to be met in 
numerical terms; in addition, the selection process must be transformed, such that those who withdraw are the weaker politicians, while those retained and newly recruited represent the best that society has to offer. The first step toward improving the quality of a legislature is therefore to assess the merit of those already present, to determine in a fair and transparent way which politicians should continue and which should step down. Thus, quotas for men necessitate careful scrutiny of men's qualifications and job performance. This ideal is easily stated but less easily achieved, because the traditional standards against which men might be measured are not necessarily the best ones for determining which legislators are most fit to serve as democratic representatives. Therefore, to ensure optimal quality, we require a reappraisal of the qualities needed to be an effective representative.

\section{RETHINKING THE CRITERIA FOR BEING A GOOD REPRESENTATIVE}

Identifying appropriate criteria for being a good representative presents multiple challenges. Normatively, it is difficult to isolate the key qualities required of a good representative without inadvertently drawing on (male-dominated) precedents. Empirically, it is difficult to apply abstract concepts of merit to specific individuals, especially when considering prospective as well as current politicians. This section considers how existing studies have grappled with these issues, before proposing paths for future research.

Many theoretical works on representation focus on relatively abstract criteria for determining good representatives, such as integrity, sound judgment, or rational decision making. For example, there is debate about the extent to which representatives should be delegates, enacting the stated preferences of constituents, or trustees, following their own judgments (Eulau et al. 1959). Hanna Pitkin's (1967) seminal work extends the debate, illuminating the different requirements of representative democracy. She highlights how representatives may stand and act for their constituents, and introduces the notions of descriptive, substantive, and symbolic representation. These definitions are instructive when assessing the capacity both of individual representatives and of institutions such as legislatures to serve the needs of representative democracy. Mansbridge (2003) builds on Piktin's definitions. She introduces concepts such as anticipatory, gyroscopic, and surrogate representation. Anticipatory representation assumes that citizens base their votes on the future promises made by candidates, in opposition to promissory representation, which evaluates promises kept since the previous election; Przeworski, Stokes, and Manin (1999) discuss similar concepts in the form of mandate and accountability views of elections. Gyroscopic representatives look within themselves to their own beliefs to inform their judgments, and representatives who share beliefs and experiences with their constituents might be best placed to perform this type of representation. Surrogate representation accounts for scenarios whereby citizens feel most represented by politicians from beyond their own constituency, thus highlighting the importance of diversity across the legislature as a whole. Rehfeld (2009) and Saward (2010) present a more nuanced discussion of these concepts and demonstrate their applicability to representation beyond the electoral context.

Although these studies are important for understanding the relationship between representative and constituent, they are less instructive about the specific qualities that best qualify individuals to serve as representatives (Rehfeld 2010). Dovi (2007) offers an important advance by developing several key criteria for measuring a "good representative." These include the virtues of fair-mindedness, critical trust building, and good gatekeeping. Dovi's criteria are unbiased, but are more useful for judging retrospectively the attributes of those already in office than for identifying the potential of candidates not yet elected. Although these criteria might therefore help identify male representatives who need to be deselected to implement a quota for men, they do not overcome the problem faced by women and other out-groups of proving their credentials prior to election. It is unsatisfactory to remove men from office using criteria that cannot guarantee that the representatives replacing them will be any better qualified. However, Dovi also argues that democratic representation requires the legitimacy of institutions, and this is undermined by the exclusion of marginalized groups; hence, the quality of representation must be considered both at an individual and a collective level.

These important theoretical advances concerning democratic norms of representation need to be integrated into candidate selection procedures, both when considering new candidates and deciding whether to reselect candidates. Current criteria deployed by political parties to recruit candidates include availability of resources, such as the time and money necessary to run a successful campaign; charisma; eloquence and the ability to defend an argument in public; media appeal; ability to work a crowd; intelligence; and networks. Parties may also place a premium on party loyalty, sometimes favoring a compliant candidate over one willing to defend constituents' interests. Murray (2010c) found that these attributes were cited more frequently than professional background or educational attainment as being essential criteria for selection (see also Hazan and Rahat 2010).

Yet, many empirical studies of candidate quality still focus on income and education rather than the character traits driving candidate selection (Baltrunaite et al. 2012; Besley et al. 2012; Galasso and Nannicini 2011; Júlio and Tavares 2010; Kotakorpi and Poutvara 2011). Representatives often follow a particular (usually elite) path involving specific educational qualifications from selective establishments (such as Ivy League universities), certain careers (such as business and law), and certain springboard positions (such as coveted, usually male-dominated positions within local or party politics). Even allowing for some variation depending on the nature of the selectorate and electoral system, the current criteria for successful entry into politics 
are rather narrow. They focus on privilege and insider knowledge, without emphasizing the need to share and understand citizens' concerns. Traditional notions of a good representative do not best reflect the needs of contemporary societies in all their diversity.

It is also difficult to evaluate merit conclusively using the existing criteria, so claims of women's inferiority cannot easily be disproved. Studies attempting to compare men's and women's preparedness for office have produced mixed results (Black and Erickson 2000; Curtin 2008; Escobar-Lemmon and TaylorRobinson 2009; Saint-Germain 1993). Verge (2011) and Franceschet and Piscopo (2012) found that women tend to have higher levels of education than men, supporting the hypothesis that the bar is raised higher for women. In contrast, O'Brien (2012) found little difference between the sexes, and Murray (2010b) found that women have slightly different professional backgrounds and less prior political experience on average than men. But the main limitation of all these studies is that the means of judging "merit" are somewhat arbitrary, given the understandable focus on objective, measurable criteria such as education, profession, and prior political experience. Such measures cannot gauge many of the more subjective criteria that also influence a candidate's chances of success. The challenge of identifying criteria that are objective, measurable, and meaningful makes it difficult to draw strong conclusions regarding the relative merit of male and female candidates.

The criteria for judging candidate quality may also contain an inherent male bias. The measure of a good candidate often stems from an evaluation of what came before, using prior examples of successful candidates as models for future aspirants. If the status quo is predominantly male, there is a risk that selectors will (perhaps inadvertently) favor qualities more commonly found in men. Norris and Lovenduski recognize this problem, arguing that "if selectors base their assumptions about suitable applicants on their image of established MPs this may produce a systematic bias in favor of maintaining the status quo" $(1995,127)$. Taylor concurs, stating that "one way discrimination is perpetuated is by the dominance of elite white men over. . .the idea of what counts as merit" (1991, 233, emphasis in original). Bacchi (1996) argues that, though ill defined, these criteria often go unquestioned. Franceschet, Krook, and Piscopo $(2012,11)$ further note that "assessing female politicians' backgrounds and preparations according to norms established by men's longstanding participation risks ignoring or discounting the types of qualifications women do bring to politics, such as extensive backgrounds in grassroots or community organizing." Traditional definitions of "qualification" and "competence" therefore may exclude criteria that are important for performing the role of a democratic representative.

Furthermore, discriminatory societal attitudes may color our judgment when assessing "outsider" groups as prospective representatives. When definitions of merit are applied to groups other than elite men, stereotypes about the competence of women and other outsiders may inhibit people's perceptions of these outsiders as meritorious (Kanter 1977). Young (2000) argues that structural discrimination has led both to an underestimation of the capacities of out-groups such as women and ethnic minorities, and the use of criteria based on elite male norms that are harder for others to meet. Women may therefore find themselves being judged unfavorably against criteria that men are assumed more naturally to possess.

However, these problems should not undermine efforts to generate unbiased criteria for evaluating election candidates-on the contrary, the presence of underlying biases only reinforces the need to develop objective criteria rather than relying on subjective judgments. As Dovi $(2007,14)$ argues, "to remain silent about the proper criteria for choosing representatives is to ignore the fact that democratic citizens will not always bring proper standards to bear in evaluating their representatives. Contemporary political theory should not be afraid to challenge the judgments of democratic citizens by offering guidelines for assessing individual representatives." Developing criteria that are appropriate, objective, unbiased, and measurable is an immense undertaking that is beyond the scope of this article. The key aims here are to highlight the need for further research in this area and to suggest some steps forward.

When considering which traits and backgrounds might best qualify an individual for electoral office, one option is to consider the core functions of a representative, thereby ensuring that the qualities demanded correspond to the needs of the role. This approach refocuses criteria away from subjective impressions based on the status quo and toward the objective requirements of representation. Representatives serve a symbolic role as the embodiment of democracy, speaking for those who are not themselves present. They have a discursive and deliberative function, enabling the voicing of different perspectives to ensure that all views are taken into account when policies are debated. They make decisions about policies, validating policy outcomes. Finally, they act as conduits of information, relaying ideas from constituents to fellow decision makers and then explaining and defending decisions made to their constituents. Although the exact nature of these roles might vary depending on the strength of political parties and the relationship between legislatures and executives, these four core roles are common to all representatives.

The successful performance of these roles depends both on the quality of the individual representatives and on their collective capacity to represent society. To be accepted as symbols of democracy, representatives must be of the people. If the collective body of representatives looks too different from the society that it purports to represent, there is a risk that excluded groups will no longer perceive the representative process to be legitimate. Thus, connectedness between representatives and represented is necessary to promote symbolic representation. To fulfill a deliberative function, representatives must be aware of the diverse needs of their constituents and be able to articulate these effectively. Just as no representative 
can embody full descriptive representation as an individual, neither can any individual defend all viewpoints simultaneously. In both cases, diversity at the aggregate level is essential for promoting substantive representation and ensuring that no identity or viewpoint is systematically excluded (Mansbridge 1999). Making decisions requires sound judgment, and conveying information to and from citizens requires excellent communication and interpersonal skills. Thus, both collective diversity and individual talent are essential to enable institutions to represent citizens effectively. Quotas for men would help enhance both of these dimensions of good representation.

Focusing on the core functions of a representative also reveals that some of the measures used to evaluate the ideal candidate may be superfluous. For example, the case for favoring prestigious careers in commerce or law is not persuasive. Nor is personal ambition necessarily an advantage in this context. Representatives are expected to defend the interests of their constituents and to promote the common good; if they instead prioritize their own advancement, they may be seen to be violating the principles of representative democracy. Furthermore, the importance of including a cross-section of society is clear if the symbolic and deliberative elements of representation are to be performed effectively. Lived experience of common concerns, authenticity, and empathy for the needs of others are all qualities that would serve a representative very well. However, these traditionally feminine qualities have been undervalued in assessing the fitness of individuals to represent others. Concepts of candidate merit need to be degendered, such that politiciansboth current and prospective-are evaluated on the skills actually needed to represent others, rather than on (gendered) societal expectations.

For example, when selecting election candidates, parties might favor someone who can participate regularly in campaigning activities and look unfavorably on a candidate who already has multiple demands on his or her time. Because women are more frequently charged with domestic responsibilities, including caring for children and elderly relatives, they may (be perceived to) have less availability for political campaigning. However, another way of viewing the same situation is that women in this position show skill in managing time and juggling competing priorities. Their desire to engage in politics despite other demands on their time could be viewed as evidence of their commitment and motivation.

Similarly, a man involved in corporate networks might be viewed more positively than a woman involved in childcare networks. Yet the woman might have been resourceful and adept in finding creative solutions to complex caring arrangements, as well as in working collaboratively with others and harmonizing many different schedules. These are not negligible qualities from a political perspective, and they are also skills that reflect the daily reality of many parents. Thus, a female candidate in this situation might be more closely attuned to the policy needs and personal experiences of many citizens-arguably, qualities that would benefit any policy maker. Yet such skills tend to be overlooked by selectorates in favor of more "traditional," prestigious demonstrations of competence, as evidenced by the types of candidate selected and prior research on candidate selection preferences (Krook 2006; Niven 1998; Norris and Lovenduski 1995).

Clearly, much more research is required into what constitutes "merit" and which qualities would best enable representatives to perform their function at the individual and collective level. The absence of fully reconceptualized criteria for determining the quality of legislators does not mean that it is too early to be talking about quotas for men. The process of redefining politics is iterative; quotas for men help stimulate debate on how best to achieve a meritocracy, which in turn will assist the process of refining our concepts of merit.

\section{IMPROVING MEN'S SUBSTANTIVE AND SYMBOLIC REPRESENTATION}

In addition to encouraging greater scrutiny of male politicians and providing an impetus for rethinking candidate selection criteria, a third benefit of reframing gender quotas is to advance a neglected area of representation, namely the substantive and symbolic representation of men. Prior debate has focused almost exclusively on women, with research considering linkages between the descriptive, substantive, and symbolic representation of women. The three types of representation are usually considered mutually reinforcing, although it is acknowledged that descriptive representation may not be sufficient to ensure substantive or symbolic representation, especially where male-dominated political cultures remain entrenched (Crowley 2004; Franceschet, Krook, and Piscopo 2012; Hawkesworth 2003). One of the central arguments supporting quotas for women is therefore that they might facilitate (even if they cannot guarantee) an increase in the substantive representation of women. Women have recognized interests, although their definition is widely contested (Diamond and Hartsock 1981; Dovi 2002; Sapiro 1981). Male legislators can serve as critical actors for women (Childs and Krook 2009), but the presence of women is also necessary to ensure that women's perspectives are fully articulated and defended, especially on issues that remain uncrystallized (Mansbridge 1999).

In contrast, the substantive representation of men attracts little public or scholarly attention. Because men are the dominant group, it is taken as a given that their interests will be understood and defended adequately by legislators. Men's descriptive overrepresentation has triggered complacency concerning their substantive and symbolic representation. Men's interests have not been subjected to the same intense scrutiny and debate and are less clearly defined. Yet, just as "women's interests" are heterogeneous, men also have diverse, gender-specific interests that may not always be represented adequately by a male-dominated legislature. Bacchi (1996) and Collinson and Hearn (2005) caution 
that men should not be viewed as a homogeneous category and that important differentiations among men should not be overlooked. In one of the few studies to focus explicitly on men's interests, Pease (2002) makes the case that, as with women, men's interests are not universal and are not always best served by patriarchy or the status quo. Dovi $(2007,35)$ recognizes that descriptive representatives of historically disadvantaged groups may overlook the interests of certain subgroups; the same may be true for subgroups of historically advantaged groups. More attention therefore needs to be paid to the diversity of male interests, recognizing that not all of these interests will be served by the status quo.

Similarly, although men may not feel excluded as a category from democratic institutions, subgroups of men may remain symbolically underrepresented. LeBlanc (2009) highlights how many Japanese men are unable to access politics despite the heavy male domination of politics in Japan. LeBlanc argues that gendered expectations constrain not only women but also men, resulting in obligatory performances of masculinity that serve to exclude most men. More generally, the exclusion from politics of many men who do not conform to the gendered, racial, and class norms of most legislatures may explain why dissatisfaction with democratic institutions is prevalent among men as well as women (Anderson and Guillory 1997).

Predominantly male legislatures can create environments that engender a particular kind of masculinity based on aggression, confidence, virility, and power (Grey 2002). Testosterone-fuelled debates on the floor may be combined with raucous jeers, shouting down opponents, and trading insults, plus an emphasis on masculine pursuits in more informal arenas, such as smoking rooms and a culture of heavy drinking (Htun 2005). Research on masculinities and organizational culture indicates that male-dominated environments can be intimidating for men as well as women, with men compelled to perform a certain type of masculinity in order to conform to the dominant culture, even when this does not come naturally (Collinson 1988; Collinson and Hearn 2005; Kanter 1977). Increasing the presence of women may help improve the behavior of male legislators and foster a working environment that is more respectful. ${ }^{5}$ Women may have more scope than men to disrupt and transform traditional patterns of masculinity within politics.

LeBlanc claims that "if men, because they are men, find it difficult to practice certain kinds of important politics, then a political world in which few women participate is gravely distorted-not only because women's voices are missing but also because gender expectations repress men's ability to speak for the full diversity of political needs men have" (2009, 43, emphasis in original). Curbing the numbers of men might therefore produce a more pleasant and productive legislative culture for both sexes.

\footnotetext{
5 Author's interviews with members of the French National Assembly, Paris, January-June 2011.
}

Correcting an overly masculinized culture may also enhance the substantive representation of men's interests. All policy areas are potentially gendered (Daly 2005; Walby 2005), and men's interests are already embedded within policy processes and outcomes. However, there are policy areas where men have distinctly gendered interests that require policy intervention. These include health care, where men's needs differ considerably from women; education, where attainment by boys has fallen behind girls in many subjects and countries; and paternity, where men have particular interests as fathers. Essentialist views on what men want and need may thrive unchallenged, even when this is to the detriment of some men (Kenny 2011; Messner and Solomon 2007). This is particularly the case when men have needs that contradict the dominant model of masculinity.

If the culture becomes more inclusive and the requirement to perform masculinity is removed, the legislative space is then more open to discussion of sensitive issues that might otherwise create embarrassment for men. For example, an aggressively masculine legislature might ridicule a man seeking to discuss the needs of fathers who wish to be primary or equal caregivers for their children. Consequently, important policies facilitating the role of fathers, such as paternity leave, flexible working conditions, and career breaks, might be sidelined in favor of focusing on the needs of mothers. Failure to pay sufficient attention to such issues can be detrimental to all of society. Policies obliging women to be the primary caregivers result in heavier caring burdens and damaged careers, while fathers and children are deprived of time together unless fathers exit the labor market.

In another example, mental health problems are frequently perceived as taboo, and an overly masculinized political culture might struggle to discuss the emotional needs of men. Yet we know that these needs are very real: Men are four times more likely than women to commit suicide, in part due to difficulty with discussing problems and admitting when they need help (Murphy 1998). Providing counseling and support for men and training public servants such as teachers, health care professionals, and social workers to encourage males to express emotions are all fundamental to improving men's health. Cultural taboos preventing the frank discussion of such issues might more easily be shattered within a more gender-balanced legislature. Indeed, women might even become critical actors for men on such issues. Men have benefited from substantive representation by women on potentially embarrassing issues such as testicular cancer (May 2004). Men may therefore have an "enlightened self-interest" in supporting quotas for men (Pease 2002, 166).

Although a better gender balance may be necessary to enhance the substantive representation of men, ingrained structural gender inequality and power imbalances are difficult to overturn even as women's numbers increase (Bauer and Britton 2006; Childs and Krook 2008). An advantage of reframing gender quotas as quotas for men is that this challenges existing norms, which in turn can help degender institutions. 


\section{CONCLUSION}

This article argues for a new way of approaching gender quotas. Reconceptualizing them as quotas for men alters the parameters of the debate on quotas: The frames of reference shift from the problem of female underrepresentation to that of male overrepresentation. Although both problems exist in perfect tandem and are equally important, the former is privileged in debates on quotas at the expense of the latter. An undesirable consequence of placing the emphasis on women is that women are framed as the "other" or the "outsider group" against a dominant male norm. As a result, pressure is placed on women to justify their presence in politics through questioning women's qualifications, attributes, and fitness to govern. Women may find themselves expected to provide "added value" and risk being perceived as inferior candidates who were selected only on the basis of sex rather than merit. However, the hurdles currently facing women candidates mean that the reverse is actually true: Men are the beneficiaries of preferential sex selection, whereas women have to be exceptional to overcome social, structural, and political barriers to office.

Quotas for men offer three major benefits. The first is that shifting the focus from a minimum presence of women to a maximum presence of men also shifts the burden of proving competence from women to men. Previously, the myth of meritocracy has allowed men to benefit from a presumption of competence, with their qualifications for office largely evading scrutiny. The long-term male domination of politics also means that both men and women are held to standards based on male norms. Quotas for men challenge the notion that the constant overrepresentation of men is the product of meritocracy, and reduce the stigma of being a "quota woman."

The main purpose of quotas for men is to increase the quality of representation for everybody. This would be achieved by controlling the numbers of politicians drawn from oversubscribed subsets of the population and expanding the talent pool to ensure that the full range of talent is utilized. Opening up political recruitment into a fully competitive process would promote a truer meritocracy and a more thriving democracy. However, achieving this goal would require a means for judging merit. It is highly questionable whether the criteria by which we currently evaluate politicians are the optimal measures for identifying the best possible representatives. Updating these criteria to reflect the needs of contemporary representative democracy would potentially transform our understanding of what it means to represent. Reducing the emphasis on traditional privilege, and refocusing it on the ability to understand and articulate the needs of ordinary citizens, offers the second advantage of quotas for men: to improve the representative process for all while enabling women to compete on more equal terms with men.

In addition to calling for a renewed debate on the criteria for assessing representatives, this article indicates the need for a new research agenda exploring the substantive representation of men. This is an important but neglected topic of research due to the erroneous assumption that men's interests are fully catered for within existing male-dominated politics. An important step in overcoming the pernicious effects of patriarchy is recognizing that its effects are detrimental to men as well as women, and mobilizing both sexes to seek the benefits that come from a more gender-equal society. The final benefit of quotas for men is that they offer a significant advance toward this goal.

\section{REFERENCES}

Anderson, Christopher, and Christine Guillory. 1997. "Political Institutions and Satisfaction with Democracy." American Political Science Review 91(1): 66-81.

Atkeson, Lonna Rae. 2003. "Not All Cues Are Created Equal: The Conditional Impact of Female Candidates on Political Engagement." Journal of Politics 65(4): 1040-61.

Bacchi, Carol. 1996. The Politics of Affirmative Action. Thousand Oaks, CA: Sage.

Bacchi, Carol. 2006. "Arguing for and against Quotas: Theoretical Issues.” In Women, Quotas and Politics, ed. Drude Dahlerup. London: Routledge, 32-52.

Baldez, Lisa. 2004. "Elected Bodies: Gender Quota Laws for Legislative Candidates in Mexico." Legislative Studies Quarterly 29 (May): 231-58.

Baldez, Lisa. 2006. "The Pros and Cons of Gender Quota Laws." Politics \& Gender 2(1): 102-09.

Bale, Tim, and Daniele Caramani. 2010. "Political Data in 2009." European Journal of Political Research 49 (7-8): 855-67.

Baltrunaite, Audinga, Piero Bello, Alessandra Casarico, and Paola Profeta. 2012. "Gender Quotas and the Quality of Politicians." Mimeo, Bocconi University.

Bauer, Gretchen, and Hannah E. Britton, eds. 2006. Women in African Parliaments. Boulder, CO: Lynne Rienner.

Besley, Timothy, Olle Folke, Torsten Persson, and Johanna Rickne. 2012. "Gender Quotas and the Crisis of the Mediocre Man." Mimeo, Centre for Economic Policy Research.

Bhavnani, Rikhil R. 2009. "Do Electoral Quotas Work after They Are Withdrawn? Evidence from a Natural Experiment in India." American Political Science Review 103(1): 23-35.

Bjarnegård, Elin. 2013. Gender, Informal Institutions and Political Recruitment. Basingstoke: Palgrave.

Black, Jerome H., and Lynda Erickson. 2000. "Similarity, Compensation, or Difference? A Comparison of Female and Male OfficeSeekers." Women \& Politics 21(4): 1-38.

Campbell, Rosie, Sarah Childs, and Joni Lovenduski. 2010. "Do Women Need Women Representatives?" British Journal of Political Science 40(1): 171-94.

Caramani, Daniele, Kevin Deegan-Krause, and Rainbow Murray. 2011. "Political Data in 2010." European Journal of Political Research 50 (7-8): 869-87.

Carter, David, Betty Simkins and W. Gary Simpson. 2003. "Corporate Governance, Board Diversity, and Firm Value." Financial Review 38(1): 33-53.

Carver, Terrell. 1996. Gender Is Not a Synonym for Women. Boulder, CO: Lynne Rienner.

Celis, Karen. 2006. "Substantive Representation of Women: The Representation of Women's Interests and the Impact of Descriptive Representation in the Belgian Parliament (1900-1979)." Journal of Women, Politics \& Policy 28(2): 85-114.

Celis, Karen, Sarah Childs, Johanna Kantola, and Mona L. Krook. 2008. "Rethinking Women's Substantive Representation." Representation 44(2): 99-110.

Celis, Karen, Mona Lena Krook, and Petra Meier. 2011. "The Rise of Gender Quota Laws: Expanding the Spectrum of Determinants for Electoral Reform." West European Politics 34(3): 514-30.

Childs, Sarah. 2004. New Labour's Women MPs. New York: Routledge.

Childs, Sarah. 2006. "The House Turned Upside Down? The Difference Labour's Women MPs Made." In Representing Women 
in Parliament, eds. Marian Sawer, Manon Tremblay, and Linda Trimble. Oxford: Routledge, 152-67.

Childs, Sarah, and Mona L. Krook. 2008. "Critical Mass Theory and Women's Political Representation.” Political Studies 56(3): 72536.

Childs, Sarah, and Mona L. Krook. 2009. "Analyzing Women's Substantive Representation: From Critical Mass to Critical Actors." Government and Opposition 44(2): 125-45.

Childs, Sarah, and Paul Webb. 2012. Sex, Gender and the Conservative Party. Basingstoke: Palgrave.

Childs, Sarah, and Julie Withey. 2006. "The Substantive Representation of Women: The Case of the Reduction of VAT on Sanitary Products." Parliamentary Affairs 59(1): 10-23.

Collinson, David. L. 1988. "“Engineering Humour': Masculinity, Joking and Conflict in Shop-floor Relations." Organization Studies 9(2): 181-99.

Collinson, David L., and Jeff Hearn. 2005. "Men and Masculinities in Work, Organizations, and Management." In Handbook of Studies on Men and Masculinities, eds. Michael S. Kimmel, Jeff Hearn, and Robert W. Connell. Thousand Oaks, CA: Sage.

Crowley, Jocelyn Elise. 2004. "When Tokens Matter." Legislative Studies Quarterly 29(1): 109-36.

Curtin, Jennifer. 2008. "Comparing Pathways to Power: Women and Political Leadership in New Zealand and Australia." In Public Leadership: Perspectives and Practices, eds. Paul 't Hurt and John Uhr. Canberra: Australia National University Press, 265-74.

Dahlerup, Drude. 2006. "Introduction.” In Women, Quotas and Politics, ed. Drude Dahlerup. London: Routledge, 3-31.

Dahlerup, Drude. 2007. "Electoral Gender Quotas: Between Equality of Opportunity and Equality of Result." Representation 43(2): 73-92.

Dahlerup, Drude, and Lenita Freidenvall. 2005. "Quotas as a 'Fast Track' to Equal Representation for Women." International Feminist Journal of Politics 7(1): 26-48.

Dahlerup, Drude, and Lenita Freidenvall. 2010. "Judging Gender Quotas: Predictions and Results." Policy and Politics 38(3): 40725.

Daly, Mary. 2005. "Gender Mainstreaming in Theory and Practice." Social Politics 12(3): 433-50.

Denis, Daphnee. 2012. "Sun Rises, French Female Minister Gets Heckled, Sun Sets." Slate, July 19. http://www.slate.com/blogs/xx_ factor/2012/07/19/cecile_duflot_and_the_floral_dress_just_ another_day_in_the_french_parliment.html. Accessed August 18, 2013.

Diamond, Irene, and Nancy Hartsock. 1981. "Beyond Interests in Politics." American Political Science Review 75(3): 717-21.

Dollar, David, Sandra Fisman, and Roberta Gatti. 2001. "Are Women Really the 'Fairer' Sex? Corruption and Women in Government." Journal of Economic Behavior and Organization 46: 423-29.

Dovi, Suzanne. 2002. "Preferable Descriptive Representatives: Will Just Any Woman, Black, or Latino Do?" American Political Science Review 96(4): 729-43.

Dovi, Suzanne. 2007. The Good Representative. Malden, MA: Blackwell.

Elliott, Cath. 2011. "Cameron's 'Calm Down, Dear' Is a Classic Sexist Put-down." The Guardian, April 27.

Escobar-Lemmon, Maria, and Michelle Taylor-Robinson. 2009. "Getting to the Top: Career Paths of Women in Latin American Cabinets." Political Research Quarterly 62(4): 685-99.

Eulau, Heinz, John C. Wahlke, William Buchanan, and Leroy C. Ferguson. 1959. "The Role of the Representative: Some Empirical Observations on the Theory of Edmund Burke." American Political Science Review 53(3): 742-56.

Falk, Erika. 2008. Women for President: Media Bias in Eight Campaigns. Urbana: University of Illinois Press.

Franceschet, Susan, Mona Lena Krook, and Jennifer M. Piscopo, eds. 2012. The Impact of Quotas on Women's Descriptive, Substantive, and Symbolic Representation. New York: Oxford University Press.

Franceschet, Susan, and Jennifer M. Piscopo. 2008. "Gender Quotas and Women's Substantive Representation: Lessons from Argentina." Politics \& Gender 4(3): 393-426.

Franceschet, Susan, and Jennifer M. Piscopo. 2012. "Gender Quotas and Political Backgrounds." In The Impact of Quotas, eds. Susan
Franceschet, Mona Lena Krook, and Jennifer M. Piscopo. New York: Oxford University Press, 43-56.

Franceschet, Susan, and Jennifer M. Piscopo. 2014. "Sustaining Gendered Practices? Power, Parties, and Elite Political Networks in Argentina." Comparative Political Studies 47(1): 85-110.

Galasso, Vincenzo, and Tommaso Nannicini, 2011. "Competing on Good Politicians." American Political Science Review 105(1): 7999.

Grey, Sandra. 2002. "Does Size Matter? Critical Mass and New Zealand's Women MPs." Parliamentary Affairs 55(1): $19-29$.

Hawkesworth, Mary. 2003. "Congressional Enactments of RaceGender: Towards a Theory of Raced-Gendered Institutions." American Political Science Review 97(4): 529-50.

Hazan, Reuven Y., and Gideon Rahat. 2010. Democracy within Parties: Candidate Selection Methods and Their Political Consequences. Oxford: Oxford University Press.

Henn, Matt, Mark Weinstein, and Sarah Hodgkinson. 2007. "Social Capital and Political Participation: Understanding the Dynamics of Young People's Political Disengagement in Contemporary Britain." Social Policy and Society 6(4): 467-79.

Htun, Mala N. 2005. "Why Women, But Not Blacks or Indians, Got Quotas in Politics in Latin America." Paper presented at the Annual Meeting of the Midwest Political Science Association, Chicago.

Jones, Mark. 1998. "Gender Quotas, Electoral Laws, and the Election of Women." Comparative Political Studies 31(1): 3-21.

Júlio, Paolo, and José Tavares. 2010. "The Good, the Bad and the Different: Can Gender Quotas Raise the Quality of Politicians?" Mimeo, Centre for Economic Policy Research.

Kanter, Rosabeth Moss. 1977. Men and Women of the Corporation. New York: Basic Books.

Karam, Azza. 1999. "Beijing +5: Women's Political Participation." Paper presented at the UNDP Meeting on Women and Political Participation, New Delhi, India.

Karp, Jeffrey A., and Susan A. Banducci. 2008. "When Politics Is Not Just a Man's Game: Women's Representation and Political Engagement." Electoral Studies 27: 105-15.

Kenny, Michael (2011). "The Political Theory of Recognition: The Case of the 'White Working Class.'” British Journal of Politics and International Relations 14(1): 19-38.

Kotakorpi, Kaisa, and Panu Poutvaara. 2011. "Pay for Politicians and Candidate Selection: An Empirical Analysis." Journal of Public Economics 95(7-8): 877-85.

Krook, Mona Lena. 2006. "Gender Quotas, Norms, and Politics." Politics \& Gender 2(1): 110-18.

Krook, Mona Lena. 2009. Quotas for Women in Politics: Gender and Candidate Selection Reform Worldwide. New York: Oxford University Press.

Larson, Anna. 2012. "Collective Identities, Institutions, Security, and State Building in Afghanistan." In The Impact of Quotas, eds. Susan Franceschet, Mona Lena Krook, and Jennifer M. Piscopo. New York: Oxford University Press, 136-55.

Lawless, Jennifer, and Richard L. Fox. 2010. It Still Takes a Candidate: Why Women Don't Run for Office. Cambridge: Cambridge University Press.

Lawrence, Regina, and Melody Rose. 2010. Hillary Clinton's Race for the White House. Boulder, CO: Lynne Rienner.

LeBlanc, Robin. 2009. The Art of the Gut: Manhood, Power, and Ethics in Japanese Politics. Los Angeles: University of California Press.

Lovenduski, Joni. 2005. Feminizing Politics. Cambridge: Polity Press. Mansbridge, Jane. 1999. "Should Blacks Represent Blacks and Women Represent Women? A Contingent 'Yes.'” Journal of Politics 61(3): 628-57.

Mansbridge, Jane. 2003. "Rethinking Representation." American Political Science Review 97(4): 515-28.

May, Theresa. 2004. "Women in the House: The Continuing Challenge." Parliamentary Affairs 57(4): 844-51.

Messner, Michael A., and Nancy M. Solomon. 2007. "Social Justice and Men's Interests." Journal of Sport and Social Issues 31(2): $162-78$.

Murphy, George E. 1998. "Why Women Are Less Likely than Men to Commit Suicide." Comprehensive Psychiatry 39(4) $165-75$. 
Murray, Rainbow, ed. 2010a. Cracking the Highest Glass Ceiling: A Global Comparison of Women's Campaigns for Executive Office. Santa Barbara, CA: Praeger.

Murray, Rainbow. 2010b. "Second among Unequals: A Study of Whether France's 'Quota Women' Are up to the Job.” Politics \& Gender 6(1): 93-118.

Murray, Rainbow. 2010c. Parties, Gender Quotas and Candidate Selection in France. Basingstoke: Palgrave.

Niven, David. 1998. "Party Elites and Women Candidates: The Shape of Bias." Women \& Politics 19 (2): 57-80.

Norris, Pippa, and Joni Lovenduski. 1995. Political Recruitment: Gender, Race and Class in the British Parliament. Cambridge: Cambridge University Press.

Norris, Pippa, Joni Lovenduski, and Rosie Campbell. 2004. Gender and Political Participation: The Activism Gap. London: Electoral Commission.

O’Brien, Diana Z. 2012. "Quotas and Qualifications in Uganda." In The Impact of Quotas, eds. Susan Franceschet, Mona Lena Krook, and Jennifer M. Piscopo. New York: Oxford University Press, 57 71.

O'Toole, Therese, David Marsh, and Su Jones. 2003. "Political Literacy Cuts Both Ways: The Politics of Non-participation among Young People." Political Quarterly 74(3): 349-60.

Pease, Bob. 2002. "(Re)Constructing Men's Interests." Men and Masculinities 5(2): 165-77.

Phillips, Anne. 1995. The Politics of Presence. Oxford: Oxford University Press.

Pitkin, Hanna. 1967. The Concept of Representation. Los Angeles: University of California Press.

Prügl, Elisabeth. 2012. "'If Lehman Brothers Had Been Lehman Sisters...': Gender and Myth in the Aftermath of the Financial Crisis." International Political Sociology 6(1): 21-35.

Przeworski, Adam, Susan C. Stokes, and Bernard Manin. 1999. Democracy, Accountability, and Representation. Cambridge: Cambridge University Press.

Rehfeld, Andrew. 2009. "Representation Rethought: On Trustees, Delegates, and Gyroscopes in the Study of Political Representation and Democracy." American Political Science Review 103(2): 214-30.

Rehfeld, Andrew. 2010. "On Quotas and Qualifications for Office." In Political Representation, eds. Ian Shapiro, Susan Stokes, Elisabeth Jean Wood, and Alexander Kirshner. Cambridge: Cambridge University Press, 236-68.

Reingold, Beth. 2006. "Women as Office Holders: Linking Descriptive and Substantive Representation." Paper presented at the "Political Women and American Democracy" conference, University of Notre Dame.

Saint-Germain, Michelle A. 1993. "Paths to Power of Women Legislators in Costa Rica and Nicaragua." Women's Studies International Forum 16(2): 119-38.

Sapiro, Virginia. 1981. "When Are Interests Interesting? The Problem of Political Representation of Women." American Political Science Review 75(3): 701-16.

Saward, Michael. 2010. The Representative Claim. Oxford: Oxford University Press.
Schwindt-Bayer, Leslie. 2010. Political Power and Women's Representation in Latin America. New York: Oxford University Press.

Sénac-Slawinski, Réjane. 2010. "De la parité à la diversité : entre Deuxième sexe et discrimination seconde." Modern and Contemporary France 18 (4): 431-44.

Stevens, Anne. 2012. "Comparing and Assessing Gender Effects in Political Leadership." In Comparative Political Leadership, ed. Ludger Helms. Basingstoke: Palgrave 207-26.

Sung, Hung-En. 2003. "Fairer Sex or Fairer System? Gender and Corruption Revisited." Social Forces 82(2): 703-23.

Swamy, Anand, Stephen Knack, Young Lee, and Omas Azfar. 2001. "Gender and Corruption." Journal of Developmental Economics 64(1): 25-55.

Swers, Michele L. 1998. "Are Women More Likely to Vote for Women's Issue Bills than Their Male Counterparts?" Legislative Studies Quarterly 23(3): 435-48.

Swers, Michele L. 2005. "Connecting Descriptive and Substantive Representation: An Analysis of Sex Differences in Co-sponsorship Activity." Legislative Studies Quarterly 30(3): 407-33.

Taylor, Bron R. 1991. Affirmative Action at Work. Pittsburgh: University of Pittsburgh Press.

Teigen, Mari. 2000. "The Affirmative Action Controversy." NORANordic Journal of Women's Studies 8(2): 63-77.

Tinker, Irene. 2004. "Quotas for Women in Elected Legislatures: Do They Really Empower Women?" Women's Studies International Forum 27: 531-46.

Tripp, Aili Mari, and Alice Kang. 2008. "The Global Impact of Quotas: On the Fast Track to Increased Female Legislative Representation." Comparative Political Studies 41(3): 338-61.

UNESCO Institute for Statistics. 2010. Global Education Digest 2010: Comparing Education Statistics Across the World. http:// www.uis.unesco.org/Library/Documents/GED_2010_EN.pdf.

Verba, Sidney, Nancy Burns, and Kay Lehman Schlozman. 1997. "Knowing and Caring about Politics: Gender and Political Engagement." Journal of Politics 59(4): 1051-72.

Verge, Tania. 2011. "Quotas' Effects on Political Recruitment, Candidates' Profiles, and Routes to Political Office." Paper presented at the European Conference on Gender and Politics, Budapest, Hungary.

Walby, Sylvia. 2005. "Gender Mainstreaming: Productive Tensions in Theory and Practice." Social Politics 12(3): 321-43.

Walsh, Denise. 2012. "Party Centralization and Debate Conditions in South Africa." In The Impact of Quotas, eds. Susan Franceschet, Mona Lena Krook, and Jennifer M. Piscopo. New York: Oxford University Press, 119-35.

Young, Iris Marion. 2000. Inclusion and Democracy. Oxford: Oxford University Press.

Zetterberg, Par. 2008. "The Downside of Gender Quotas? Institutional Constraints on Women in Mexican State Legislatures." Parliamentary Affairs 61(3): 442-60.

Zimmer, Lynn. 1988. "Tokenism and Women in the Workplace: The Limits of Gender-Neutral Theory." Social Problems 35(1): 64-77. 